\title{
Will coronavirus disease (COVID-19) have an impact on antimicrobial resistance?
}

Dominique L Monnet ${ }^{1}$, Stephan Harbarth ${ }^{2}$

1. European Centre for Disease Prevention and Control (ECDC), Stockholm, Sweden

2. Infection Control Program and Division of Infectious Diseases, University of Geneva Hospitals and Faculty of Medicine, Geneva, Switzerland

Correspondence: Dominique L. Monnet (dominiquel.monnet@ecdc.europa.eu)

Since the beginning of 2020 , the ongoing coronavirus disease (COVID-19) pandemic has resulted in the deaths of more than 250,000 patients in the European Union/European Economic Area (EU/EEA) and the United Kingdom alone [1]. By the end of 2020, as every year, bacterial infections with antimicrobial resistance (AMR) will have caused the deaths of more than 30,000 Europeans [2]. AMR is another ongoing pandemic that often goes unnoticed by a majority of Europeans. Larry Kerr, co-chair of the Transatlantic Task Force on Antimicrobial Resistance, recently compared the AMR pandemic to a multitude of small fires that are much less visible than the single massive firestorm that is the COVID-19 pandemic.

While experts have warned of the link between COVID19 and AMR [3-8], studies report conflicting evidence. Several studies-from, in particular, Germany, Italy and the US-have reported outbreaks or an increase in infections with and/or acquisition of multidrug-resistant bacteria during the COVID-19 pandemic [9-12]. Further studies have reported cases of antimicrobial-resistant invasive fungal infections in COVID-19 patients [13,14], and one case of azole-resistant Aspergillus spp. infection in an immunocompetent COVID-19 patient [15]. However, other studies from France and Spain did not show an increase in infections with multidrugresistant bacteria $[16,17]$, and one Italian study even saw a reduction in Clostridioides difficile infections in hospitalised patients [18]. In a rapid review, Fattorini et al. found that only $1.3 \%$ of 522 COVID-19 patients in intensive care units (ICUs), and apparently no COVID19 patients in other units, developed a healthcareassociated superinfection with antimicrobial-resistant bacteria [19].

These different experiences may just be the consequence of previous antibiotic prescribing and infection prevention and control (IPC) practices that resulted in varying background AMR prevalence, in particular in healthcare settings, in different countries $[8,20]$. Still, antibiotic prescribing and IPC practices may change during the COVID-19 pandemic and AMR could either increase or decrease as a result of these changes [5]. As pointed out by Nieuwlatt et al. [21], COVID-19 and $A M R$ are parallel and interacting health emergencies that have similarities and offer opportunities for mutual learning with regard to their control. But the question remains whether the AMR situation in Europe and elsewhere will worsen or improve as a consequence of the current COVID-19 pandemic.

We summarised various determinants that may result in either an increase or, inversely, a decrease in AMR and found them to be balanced (Table). The truth is that the impact of the COVID-19 pandemic on AMR will only become clear in the coming months and years as data gradually become available. Changes in AMR will most likely vary depending on the setting-e.g. ICUs vs other hospital units, hospital vs community settingsand possibly between countries.

\section{Keeping the momentum}

On the occasion of European Antibiotic Awareness Day (EAAD), the European Centre for Disease Prevention and Control (ECDC) will publish its annual reports on surveillance of AMR from the European Antimicrobial Resistance Surveillance Network (EARS-Net) and on surveillance of antimicrobial consumption in humans from the European Surveillance of Antimicrobial Consumption Network (ESAC-Net). Data up to 2019 are already available from the ECDC Surveillance Atlas of Infectious Diseases [20] and the ESAC-Net database [22]. The World Health Organization (WHO) Regional Office for Europe will also publish an update of its annual report of the Central Asian and European Surveillance of Antimicrobial Resistance (CAESAR) [23], including data up to 2019. The European Medicines Agency (EMA) just published its 10th report on the European Surveillance of Veterinary Antimicrobial 
TABLE A

Factors that may influence levels of antimicrobial resistance during the COVID-19 pandemic

\begin{tabular}{|c|c|c|}
\hline ype of factor & ctors that may favour an increase in AMR & e in AMR \\
\hline & $\begin{array}{l}\text { - About } 70 \% \text { of hospitalised COVID-19 patients receive antibiotics } \\
\text { [33,34] } \\
\text { - COVID-19 patients often receive empiric broad-spectrum antibiotic } \\
\text { therapy [34-36] } \\
\text { - } 16 \% \text { of hospitalised COVID-19 patients develop a secondary } \\
\text { bacterial infection [34], which will necessitate antibiotic therapy } \\
\text { - Possible increased use of azithromycin and teicoplanin (because of } \\
\text { the initial absence of clear guidelines for the treatment of COVID-19 } \\
\text { patients) }[4,6,8] \\
\text { - Difficulties in accessing advice from experts before prescribing } \\
\text { antimicrobial agents [4] } \\
\text { - Antimicrobial stewardship efforts may be undermined because of } \\
\text { high workloads and shifting priorities related to COVID-19 [37,38] } \\
\text { - Possible aggravation of existing shortages of certain narrow- } \\
\text { spectrum antimicrobial agents [39,40] }\end{array}$ & $\begin{array}{l}\text { - Bacterial co-infection (estimated on } \\
\text { presentation) in only } 3.5 \% \text { ( } 95 \% \text { Cl: } 1-7 \% \text { ) of } \\
\text { COVID-19 patients [33] } \\
\text { - Bacterial/fungal infection in only } 8 \% \text { of } \\
\text { hospitalised COVID-19 patients vs } 11 \% \text { in non- } \\
\text { COVID-19 patients [34]; the percentage for COVID- } \\
19 \text { patients may be underestimated because many } \\
\text { may have received empiric antimicrobial therapy } \\
\text { [41] } \\
\text { - Only } 1.3 \% \text { of CoVID-19 patients in ICUs, and } \\
\text { apparently no patients in other units, developed } \\
\text { a healthcare-associated superinfection with } \\
\text { antimicrobial-resistant bacteria [19] } \\
\text { - Postponed planned surgical interventions } \\
\text { result in fewer antibiotic courses for surgical } \\
\text { prophylaxis [42] } \\
\text { - Fewer emergency and planned hospital } \\
\text { admissions [43,44], including chronically ill } \\
\text { patients (e.g. oncology patients, diabetic patients, } \\
\text { transplant patients), resulting in fewer antibiotic } \\
\text { prescriptions }\end{array}$ \\
\hline $\begin{array}{l}\text { Infection } \\
\text { prevention } \\
\text { and control } \\
\text { hospitals }\end{array}$ & $\begin{array}{l}\text { - Difficulties for HCWs in adhering to standard IPC precautions } \\
\text { because of long shifts wearing the same PPE [45] and possible } \\
\text { shortages of certain equipment [5] } \\
\text { - Focus of HCWs on self-protection (e.g. universal gloving practices) } \\
\text { rather than on preventing cross-transmission between patients } \\
\text { - In COVID-19 cohort units and ICUs, sessional use of PPE, e.g. long- } \\
\text { sleeved gowns that prevent effective hand hygiene [46] and gloves } \\
\text { that may not be changed between patients [45] } \\
\text { - Overcrowded facilities and possible staff shortages leading to low } \\
\text { HCW-to-patient ratios [5] } \\
\text { - Shortages of HCWs with appropriate IPC training [4] } \\
\text { - Longer hospital stays for COVID-19 patients [5] } \\
\text { - Traditional IPC efforts may be temporarily discontinued, including } \\
\text { those targeting antibiotic-resistant bacteria, e.g. decreased } \\
\text { frequency of screening for carriage of MDROs and difficulties in } \\
\text { isolating or cohorting MDRO-positive patients [4,47] } \\
\text { - Decreased laboratory capacity to detect AMR carriage, e.g. for } \\
\text { processing rapid tests for MDROs, because resources are focused on } \\
\text { SARS-CoV-2 diagnosis [4] }\end{array}$ & $\begin{array}{l}\text { - Isolation of COVID-19 patients with enhanced } \\
\text { standard precautions, e.g. increased hand } \\
\text { hygiene and use of PPE, plus universal } \\
\text { chlorhexidine bathing protocols for patients in } \\
\text { ICUs [5] } \\
\text { - Increased disinfection of the environment [4,5] } \\
\text { - COVID-19 patients are often cohorted in one } \\
\text { single unit and cared for by the same group of } \\
\text { HCWs [5] } \\
\text { - Fewer emergency and planned hospital } \\
\text { admissions [43,44], including chronically ill } \\
\text { patients (e.g. oncology patients, diabetic } \\
\text { patients, transplant patients), resulting in lower } \\
\text { colonisation pressure by fewer carriers of MDROs } \\
\text { - Fewer transfers from long-term care facilities } \\
\text { may lead to fewer cycles between long-term care } \\
\text { facilities and hospitals [5] } \\
\text { - Construction of new COVID-19 facilities without } \\
\text { an established reservoir of MDROs [5] }\end{array}$ \\
\hline
\end{tabular}

Consumption with data from 2018 [24]. ECDC, EMA and the European Food Safety Authority are currently working on a third Joint Interagency Antimicrobial Consumption and Resistance Analysis report, to be published in 2021, which will include a detailed One Health analysis based on data from 2016 to 2018. At the global level, the latest WHO Global Antimicrobial Resistance Surveillance System Early Implementation Report 2020 on AMR has data from 2018 [25].

Unfortunately, more recent data are not yet available from these networks to assess the impact of COVID19 on AMR. As of December 2018, only nine EU/EEA countries used machine-to-machine links for reporting data from clinical laboratory information management systems to a national database on EU-notifiable diseases and on AMR, respectively [26]. While the collection and analysis of certain data requires time, we obviously need to implement systems for AMR surveillance in Europe that can obtain data and provide results much faster, taking as examples those that have already been implemented or are being tested in some European countries or projects $[26,27]$.

In addition, specific studies will need to be performed to assess changes in antibiotic prescribing, IPC practices and their effect on AMR as a consequence of the COVID-19 pandemic. One important point that will require consideration is that the effects of changes in antibiotic prescribing and IPC practices on AMR is 
Factors that may influence levels of antimicrobial resistance during the COVID-19 pandemic

\begin{tabular}{|c|c|c|}
\hline Type of factor & Factors that may favour an increase in AMR & Factors that may favour a decrease in AMR \\
\hline $\begin{array}{l}\text { Antibiotic use in } \\
\text { the community }\end{array}$ & $\begin{array}{l}\text { - Likely increased antibiotic use in nursing homes and other long- } \\
\text { term care facilities } \\
\text { - Possible increased self-medication with antibiotics in some } \\
\text { countries or regions of the world [48] }\end{array}$ & $\begin{array}{l}\text { - Possible decreased antibiotic consumption } \\
\text { because of fewer patient consultations, e.g. for } \\
\text { self-limiting infections that would otherwise have } \\
\text { resulted in an antibiotic prescription [4] } \\
\text { - Possible decreased incidence of respiratory tract } \\
\text { infections as a consequence of decreased person- } \\
\text { to-person transmission because of lockdowns, } \\
\text { resulting in decreased antibiotic consumption } \\
\text { - Possible increased awareness of the difference } \\
\text { between viruses and bacteria, and the fact } \\
\text { that there are different types of medicines, } \\
\text { i.e. antivirals and antibiotics, respectively, for } \\
\text { different types of infections [8] } \\
\text { - Increased influenza vaccine uptake } \\
\text { may decrease the incidence of bacterial } \\
\text { superinfections after influenza }\end{array}$ \\
\hline $\begin{array}{l}\text { Hygiene } \\
\text { practices in the } \\
\text { community }\end{array}$ & $\begin{array}{l}- \text { Increased use of sanitisers and other biocidal agents and their } \\
\text { release in the environment }[3,6,8,49]\end{array}$ & $\begin{array}{l}\text { - Increased hand hygiene practices and } \\
\text { compliance in the community } \\
\text { - Increased physical distancing and use of face } \\
\text { masks } \\
\text { - Increased disinfection of the environment }\end{array}$ \\
\hline $\begin{array}{l}\text { Cross-border } \\
\text { spread }\end{array}$ & & $\begin{array}{l}\text { - Fewer patient transfers of seriously ill patients } \\
\text { between countries, resulting in less frequent } \\
\text { cross-border spread of MDROs } \\
\text { - Large decrease in international air travel, } \\
\text { resulting in decreasing risk of global } \\
\text { dissemination of antimicrobial-resistant bacteria } \\
\text { and genes from highly endemic regions }[8,50]\end{array}$ \\
\hline $\begin{array}{l}\text { Public health } \\
\text { policy making, } \\
\text { including One } \\
\text { Health }\end{array}$ & $\begin{array}{l}\text { - Shift in high-level policy making towards viral diseases and } \\
\text { preparedness for emerging viruses } \\
\text { - National plans and other initiatives to fight AMR are likely to have } \\
\text { been slowed down, temporarily discontinued or even postponed } \\
\text { because of COVID-19 public health emergencies and duties (similar } \\
\text { to the WHO Global Strategy for Containment of Antimicrobial } \\
\text { Resistance, which was launched on } 11 \text { September } 2001 \text { and went } \\
\text { largely unnoticed by the global community, without any major } \\
\text { impact on AMR activities for almost a decade, because of the } \\
\text { disproportional focus on biosecurity issues) } \\
\text { - Potential One Health impact of increased volumes of antibiotics } \\
\text { from prescriptions in humans being released in the environment } \\
\text { [3,51] }\end{array}$ & $\begin{array}{l}\text { - Gain in public and political attention for all } \\
\text { threats related to communicable diseases, } \\
\text { including already endemic issues such as AMR } \\
\text { - Possible decrease in antimicrobial consumption } \\
\text { in animals because of reduction in the size of } \\
\text { livestock herds [52], possibly combined with } \\
\text { difficulties in obtaining antibiotics }\end{array}$ \\
\hline
\end{tabular}

AMR: antimicrobial resistance; CI: confidence interval; COVID-19: coronavirus disease; HCW: healthcare worker; ICU: intensive care unit; IPC: infection prevention and control; MDRO: multidrug-resistant organism; PPE: personal protective equipment; SARS-CoV-2: severe acute respiratory syndrome coronavirus 2; WHO: World Health Organization.

unlikely to be immediate, and that the necessary delays to observe these effects-as well as the thresholds above which changes in antibiotic prescribing and IPC result in an effect-will need to be taken into account when analysing data [28]. We should learn from the COVID-19 pandemic, with its rapid turnover and use of whole genome sequencing data, and dynamic linkage of various health databases $[8,29]$. Surveillance data based on clinical samples in particular, if focused only on bloodstream infections, may provide a distorted picture of the effect of COVID-19 on AMR since the effect may only manifest itself in other clinical sites or even only in the commensal flora. This means that studies based on existing surveillance data should be complemented by well-designed cohort studies with serial surveillance swabs, e.g. in ICUs and other highrisk units.

\section{European Antibiotic Awareness Day and} World Antimicrobial Awareness Week 2020 On 18 November, we will celebrate the 13th EAAD, in partnership with the World Antimicrobial Awareness Week, from 18 to 24 November 2020. Much has happened in Europe since the first EAAD in 2008: repeated awareness campaigns took place, EU and national action plans were developed in most EU/EEA countries 
and regulatory actions, policy initiatives and interventions were enacted at EU and national levels. One example of EU regulatory action is provided in this issue by Opalska et al., who reviewed all EU post-authorisation procedures of harmonising product information for antibiotics from 2007 to 2020 . The study found that the majority resulted in a restriction of indications for antibiotics, which could have contributed to decreasing their consumption and, ultimately, AMR [30]. The authors are planning further studies on the effect of such regulatory actions on antimicrobial consumption to inform future policies.

As suggested last year by Peñalva et al., there are signs that the many actions and initiatives implemented at EU and national levels may start to show their effects on antimicrobial consumption and AMR trends [31]. Nevertheless, much remains to be done to prevent and control AMR in Europe. The most recent data from EARSNet confirm that AMR is still a serious challenge for the EU/EEA. In particular, the percentages of Enterococcus faecium from bloodstream infections that are resistant to vancomycin almost doubled between 2015 and 2019. Resistance to carbapenems-a last-line group of antibiotics-continues to be a concern, with several countries reporting carbapenem-resistance proportions above $10 \%$ in Klebsiella pneumoniae, and very much higher in Pseudomonas aeruginosa and Acinetobacter species bloodstream infections [20]. In this issue, a survey by Lötsch et al. provides further evidence on $A$. baumannii. Authors found that seven European countries report an endemic situation, while another nine report regional or inter-regional spread of specifically carbapenem-resistant $A$. baumannii, with national capacities for its surveillance and containment varying depending on the country [32]. For example, only 23 of the 37 participating European countries had a surveillance system for reporting carbapenem-resistant $A$. baumannii, 15 had national recommendations or guidelines for its control and only eight countries had a national plan for its containment-only one of which was one of the seven endemic countries.

The COVID-19 pandemic reminds us that compliance with IPC measures is critical to ensure the safety of hospitalised patients. Most IPC measures that are essential for controlling the spread of SARS-CoV-2 also contribute to reducing the spread of antimicrobialresistant bacteria; these, together with antimicrobial stewardship programmes, must be maintained and strengthened. In the midst of the COVID-19 pandemic, we certainly must not give up on our efforts to prevent and control AMR and must stay united to preserve the effectiveness of antimicrobials.

\section{Conflict of interest}

None declared.
References

1. European Centre for Disease Prevention and Control (ECDC). COVID-19 situation update for the EU/EEA and the UK, as of 12 Nov 2020. Stockholm: ECDC. [Accessed: 12 Nov 2020]. Available from: https://www.ecdc.europa.eu/en/ cases-2019-ncov-eueea

2. Cassini A, Högberg LD, Plachouras D, Quattrocchi A, Hoxha A, Simonsen GS, et al. Attributable deaths and disabilityadjusted life-years caused by infections with antibioticresistant bacteria in the EU and the European Economic Area in 2015: a population-level modelling analysis. Lancet Infect Dis. 2019;19(1):56-66. https://doi.org/10.1016/S1473 3099(18)30605-4 PMID: 30409683

3. Bengoechea JA, Bamford CG. SARS-CoV-2, bacterial coinfections, and AMR: the deadly trio in COVID-19? EMBO Mol Med. 2020;12(7):e12560. https://doi.org/10.15252/ emmm.202012560 PMID: 32453917

4. Cantón R, Gijón D, Ruiz-Garbajosa P. Antimicrobial resistance in ICUs: an update in the light of the COVID-19 pandemic. Curr Opin Crit Care. 2020;26(5):433-41. https://doi.org/10.1097/ MCC.0000000000000755 PMID: 32739970

5. Donà D, Di Chiara C, Sharland M. Multi-drug-resistant infections in the COVID-19 era: a framework for considering the potential impact. J Hosp Infect. 2020;106(1):198-9. https://doi. org/10.1016/j.jhin.2020.05.020 PMID: 32425287

6. Getahun H, Smith I, Trivedi K, Paulin S, Balkhy HH. Tackling antimicrobial resistance in the COVID-19 pandemic. Bull World Health Organ. 2020;98(7):442-442A. https://doi.org/10.2471/ BLT.20.268573 PMID: 32742026

7. McKenna M. Covid-19 may worsen the antibiotic resistance crisis. Boone: Wired. 23 Apr 2020. Available from: https://www.wired.com/story/ covid-19-may-worsen-the-antibiotic-resistance-crisis/

8. Murray AK. The novel coronavirus COVID-19 outbreak: global implications for antimicrobial resistance. Front Microbiol. 2020;11:1020. https://doi.org/10.3389/fmicb.2020.01020 PMID: 32574253

9. Kampmeier S, Tönnies H, Correa-Martinez CL, Mellmann A, Schwierzeck V. A nosocomial cluster of vancomycin resistant enterococci among COVID-19 patients in an intensive care unit. Antimicrob Resist Infect Control. 2020;9(1):154. https://doi. org/10.1186/s13756-020-00820-8 PMID: 32962759

10. Nori P, Szymczak W, Puius Y, Sharma A, Cowman K, Gialanella $P$, et al. Emerging co-pathogens: New Delhi Metallobeta-lactamase producing Enterobacterales infections in New York City COVID-19 patients. Int J Antimicrob Agents. 2020;106179:106179. https://doi.org/10.1016/j. ijantimicag.2020.106179 PMID: 32987104

11. Porretta AD, Baggiani A, Arzilli G, Casigliani V, Mariotti T, Mariottini F, et al. Increased risk of acquisition of New Delhi metallo-beta-lactamase-producing carbapenem-resistant Enterobacterales (NDM-CRE) among a cohort of COVID-19 patients in a teaching hospital in Tuscany, Italy. Pathogens. 2020;9(8):635. https://doi.org/10.3390/pathogens9080635 PMID: 32764228

12. Tiri B, Sensi E, Marsiliani V, Cantarini M, Priante G, Vernelli C, et al. Antimicrobial stewardship program, COVID-19, and infection control: Spread of carbapenem-resistant Klebsiella pneumoniae colonization in ICU COVID-19 patients. What did not work? J Clin Med. 2020;9(9):E2744. https://doi. org/10.3390/jcm9092744 PMID: 32854334

13. Chowdhary A, Tarai B, Singh A, Sharma A. Multidrugresistant Candida auris infections in critically ill coronavirus disease patients, India, April-July 2020. Emerg Infect Dis. 2020;26(11):2694-6. https://doi.org/10.3201/eid2611.203504 PMID: 32852265

14. Posteraro B, Torelli R, Vella A, Leone PM, De Angelis G, De Carolis E, et al. Pan-echinocandin-resistant Candida glabrata bloodstream infection complicating COVID-19: a fatal case report. J Fungi (Basel). 2020;6(3):163. https://doi.org/10.3390/ jof6030163 PMID: 32899996

15. Meijer EFJ, Dofferhoff ASM, Hoiting O, Buil JB, Meis JF. Azoleresistant COVID-19-associated pulmonary aspergillosis in an immunocompetent host: a case report. J Fungi (Basel). 2020;6(2):79. https://doi.org/10.3390/jof6020079 PMID: 32517166

16. Contou D, Claudinon A, Pajot O, Micaëlo M, Longuet Flandre $P$, Dubert $M$, et al. Bacterial and viral co-infections in patients with severe SARS-CoV-2 pneumonia admitted to a French ICU. Ann Intensive Care. 2020;10(1):119. https://doi.org/10.1186/ S13613-020-00736-x PMID: 32894364

17. Garcia-Vidal C, Sanjuan G, Moreno-García E, Puerta-Alcalde P, Garcia-Pouton N, Chumbita M, et al. Incidence of co-infections and superinfections in hospitalised patients with COVID-19: a retrospective cohort study. Clin Microbiol Infect. 2020;S1198743X(20)30450-X. https://doi.org/10.1016/j.cmi.2020.07.041 
18. Bentivegna E, Alessio G, Spuntarelli V, Luciani M, Santino I, Simmaco M, et al. Impact of COVID-19 prevention measures on risk of health care-associated Clostridium difficile infection. Am J Infect Control. 2020 Oct 5; S0196-6553(20)30891-9. https://doi.org/10.1016/j.ajic.2020.09.010

19. Fattorini L, Creti R, Palma C, Pantosti A, Unit of Antibiotic Resistance and Special Pathogens, Unit of Antibiotic Resistance and Special Pathogens of the Department of Infectious Diseases, Istituto Superiore di Sanità, Rome. Bacterial coinfections in COVID-19: an underestimated adversary. Ann Ist Super Sanita. 2020;56(3):359-64. https:// doi.org/10.4415/ANN_20_03_14 PMID: 32959802

20. European Centre for Disease Prevention and Control (ECDC). Surveillance Atlas of Infectious Diseases. Stockholm: ECDC. [Accessed: 23 Oct 2020]. Available from: https://atlas.ecdc. europa.eu/public/index.aspx

21. Nieuwlaat R, Mbuagbaw L, Mertz D, Burrows L, Bowdish DME, Moja L, et al. Coronavirus Disease 2019 and antimicrobial resistance: parallel and interacting health emergencies. Clin Infect Dis. 2020:ciaa773. https://doi.org/10.1093/cid/ciaa773

22. European Centre for Disease Prevention and Control (ECDC). Antimicrobial consumption database (ESAC-Net). Stockholm: ECDC. [Accessed: 23 Oct 2020]. Available from: https:// www.ecdc.europa.eu/en/antimicrobial-consumption/ surveillance-and-disease-data/database

23. World Health Organization Regional Office for Europe (WHO/ Europe). Antimicrobial resistance - Publications. Copenhagen: WHO/Europe. [Accessed: 27 Oct 2020]. Available from: https:// www.euro.who.int/en/health-topics/disease-prevention/ antimicrobial-resistance/publications

24. European Medicines Agency (EMA). European Surveillance of Veterinary Antimicrobial Consumption, 2020: sales of veterinary antimicrobial agents in 31 European countries in 2018 (EMA/24309/2020). Amsterdam: EMA; 2020. Available from: https://www.ema.europa.eu/en/documents/report/ sales-veterinary-antimicrobial-agents-31-european-countries2018-trends-2010-2018-tenth-esvac-report_en.pdf

25. World Health Organization (WHO). Global antimicrobial resistance surveillance system (GLASS) report: early implementation 2020. Geneva: WHO; 26 May 2020. Available from: https://www.who.int/glass/resources/publications/ early-implementation-report-2020/en/

26. Leitmeyer KC, Espinosa L, Broberg EK, Struelens MJ, ECDC National Focal Points laboratory e-reporting survey group members, ECDC National Focal Points laboratory e-reporting survey group. Automated digital reporting of clinical laboratory information to national public health surveillance systems, results of a EU/EEA survey, 2018. Euro Surveill. 2020;25(39):1900591. https://doi.org/10.2807/1560-7917. ES.2020.25.39.1900591 PMID: 33006301

27. Joint Programming Initiative on Antimicrobial Resistance (JPIAMR). Providing a Roadmap for Automated Infection Surveillance in Europe (PRAISE). Stockholm: JPIAMR. [Accessed: 27 Oct 2020]. Available from: https://www.jpiamr. eu/wp-content/uploads/2018/11/Summary_PRAISE.pdf

28. López-Lozano JM, Lawes T, Nebot C, Beyaert A, Bertrand X, Hocquet D, et al. , THRESHOLDS study group. A nonlinear timeseries analysis approach to identify thresholds in associations between population antibiotic use and rates of resistance. Nat Microbiol. 2019;4(7):1160-72. https://doi.org/10.1038/s41564019-0410-0 PMID: 30962570

29. Armstrong J, Rudkin JK, Allen N, Crook DW, Wilson DJ, Wyllie DH, et al. Dynamic linkage of COVID-19 test results between Public Health England's Second Generation Surveillance System and UK Biobank. Microb Genom. 2020;6(7):mgenoo0397. https://doi.org/10.1099/ mgen.0.000397 PMID: 32553051

30. Opalska A, Kwa M, Hubert Leufkens H, Gardarsdottir H. Enabling appropriate use of antibiotics: review of European Union procedures of harmonising product information, 2007 to 2020. Euro Surveill. 2020;25(45):2000035. https://doi. org/10.2807/1560-7917.ES.2020.25.45.2000035

31. Peñalva G, Högberg LD, Weist K, Vlahović-Palčevski V, Heuer O, Monnet DL, ESAC-Net Study Group, EARS-Net Study Group. Decreasing and stabilising trends of antimicrobial consumption and resistance in Escherichia coli and Klebsiella pneumoniae in segmented regression analysis, European Union/European Economic Area, 2001 to 2018. Euro Surveill. 2019;24(46):1900656. https://doi.org/10.2807/1560-7917. ES.2019.24.46.1900656 PMID: 31771708

32. Lötsch F, Albiger B, Monnet DL, Struelens M, Seifert $H$, Kohlenberg A, European Antimicrobial Resistance Genes Surveillance Network. (EURGen-Net) carbapenemresistant Acinetobacter baumannii capacity survey group. Epidemiological situation, laboratory capacity and preparedness for carbapenem-resistant
Acinetobacter baumannii in Europe, 2019. Euro Surveill. 2020;25(45):2001735.

33. Langford BJ, So M, Raybardhan S, Leung V, Westwood $D$, MacFadden DR, et al. Bacterial co-infection and secondary infection in patients with COVID-19: a living rapid review and meta-analysis. Clin Microbiol Infect. 2020;S1198-743X(20)30423-7.

34. Rawson TM, Moore LSP, Zhu N, Ranganathan N, Skolimowska $\mathrm{K}$, Gilchrist $M$, et al. Bacterial and fungal co-infection in individuals with coronavirus: A rapid review to support COVID-19 antimicrobial prescribing. Clin Infect Dis. 2020;ciaa530. https://doi.org/10.1093/cid/ciaa530

35. Beović B, Doušak M, Ferreira-Coimbra J, Nadrah K, Rubulotta F, Belliato M, et al. Antibiotic use in patients with COVID-19: a 'snapshot' Infectious Diseases International Research Initiative (ID-IRI) survey. J Antimicrob Chemother. 2020;dkaa326. https://doi.org/10.1093/jac/dkaa326

36. Abelenda-Alonso G, Padullés A, Rombauts A, Gudiol C, Pujol $M$, Alvarez-Pouso $C$, et al. Antibiotic prescription during the COVID-19 pandemic: A biphasic pattern. Infect Control Hosp Epidemiol. 2020;41(11):1371-2. https://doi.org/10.1017/ ice.2020.381 PMID: 32729437

37. Mazdeyasna $H$, Nori P, Patel P, Doll M, Godbout E, Lee K, et al. Antimicrobial stewardship at the core of COVID-19 response efforts: implications for sustaining and building programs. Curr Infect Dis Rep. 2020;22(9):23. https://doi.org/10.1007/s11908020-00734-x PMID: 32834785

38. Furukawa D, Graber CJ. Antimicrobial stewardship in a pandemic: picking up the pieces. Clin Infect Dis. 2020; ciaa1273. PMID: 32857832

39. European Association of Hospital Pharmacists (EAHP). 2018 EAHP Medicines shortages report. Medicines shortages in European hospitals. Brussels: EAHP; 2018. Available from: https://www.eahp.eu/sites/default/files/shortages reporto5online.pdf

40. ReAct - Action on Antibiotic Resistance. Shortages and AMR - why should we care? Four consequences of antibiotic shortages. ReAct; 12 Mar 2020. Available from: https:// www.reactgroup.org/news-and-views/news-and-opinions/ year-2020/shortages-and-amr-why-should-we-care-4 consequences-of-antibiotic-shortages/

41. Chang CY, Chan KG. Underestimation of co-infections in COVID-19 due to non-discriminatory use of antibiotics. J Infect. 2020;81(3):e29-30. https://doi.org/10.1016/j.jinf.2020.06.077 PMID: 32628960

42. O'Reilly-Shah VN, Van Cleve W, Long DR, Moll V, Evans FM, Sunshine JE, et al. Impact of COVID-19 response on global surgical volumes: an ongoing observational study. Bull World Health Organ. 2020;98(10):671-82. https://doi.org/10.2471/ BLT.20.264044

43. Mulholland RH, Wood R, Stagg HR, Fischbacher C, Villacampa J, Simpson CR, et al. Impact of COVID-19 on accident and emergency attendances and emergency and planned hospital admissions in Scotland: an interrupted time-series analysis. J R Soc Med. 2020;113(11):444-53. https://doi. org/10.1177/0141076820962447 PMID: 33012218

44. Sokolski M, Gajewski P, Zymlinski R, Biegus J, Berg JMT, Bor W, et al. Impact of coronavirus disease 2019 (COVID-19) outbreak on acute admissions at the emergency and cardiology departments across Europe. Am J Med. 2020;So002-9343(20)30825-1. https://doi.org/10.1016/j. amjmed.2020.08.043

45. Ford S. Infection control concerns spark new advice on PPE use during Covid-19 crisis. Braintree. Nurs Times. 2020;21. Available from: https://www.nursingtimes.net/news/policiesand-guidance/infection-control-concerns-spark-new-advice-onppe-use-during-covid-19-crisis-21-05-2020/

46. Meda M, Gentry V, Reidy P, Garner D. Unintended consequences of long-sleeved gowns in a critical care setting during the COVID-19 pandemic. J Hosp Infect. 2020;S0195 6701(20)30367-4. https://doi.org/10.1016/j.jhin.2020.07.036

47. Stevens MP, Doll M, Pryor R, Godbout E, Cooper K, Bearman G. Impact of COVID-19 on traditional healthcare-associated infection prevention efforts. Infect Control Hosp Epidemiol. 2020;41(8):946-7. https://doi.org/10.1017/ice.2020.141 PMID: 32297849

48. Nasir M, Salauddin Chowdhury ASM, Zahan T. Self-medication during COVID-19 outbreak: a cross sectional online survey in Dhaka city. Int J Basic Clin Pharmacol. 2020;9(9):1325-30. https://doi.org/10.18203/2319-2003.ijbcp20203522

49. Morgan W. Coronavirus: heavy use of hand sanitisers could boost antimicrobial resistance. London: The Conversation 17 Apr 2020. Available from: https://theconversation.com/ coronavirus-heavy-use-of-hand-sanitisers-could-boostantimicrobial-resistance-136541 
50. Kommenda N. How is the coronavirus affecting global air traffic? London: The Guardian; 3 Apr 2020. Available from: https://www.theguardian.com/world/ng-interactive/2020/ apr/o3/how-is-the-coronavirus-affecting-global-air-traffic

51. Comber SDW, Upton M, Lewin S, Powell N, Hutchinson TH.

COVID-19, antibiotics and One Health: a UK environmental risk assessment. J Antimicrob Chemother. 2020;dkaa338. https:// doi.org/10.1093/jac/dkaa338

52. Jeffery A, Newburger E. Wasted milk, euthanized livestock: Photos show how coronavirus has devastated US agriculture. New York: CNBC; 2 May 2020. Available from: https://www. cnbc.com/2020/05/02/coronavirus-devastates-agriculturedumped-milk-euthanized-livestock.html

\section{License, supplementary material and copyright}

This is an open-access article distributed under the terms of the Creative Commons Attribution (CC BY 4.0) Licence. You may share and adapt the material, but must give appropriate credit to the source, provide a link to the licence and indicate if changes were made.

Any supplementary material referenced in the article can be found in the online version.

This article is copyright of the authors or their affiliated institutions, 2020. 